\title{
ESSENCE OF BANKS FINANCIAL RESOURCES AND CLASSIFICATION
}

\author{
Oleksii MISHNOV ${ }^{1}$ \\ Kyiv National Economic University named after Vadym Hetman, Ukraine
}

\begin{abstract}
The purpose is an attempt to study the essence of the financial resources of the bank. Methodology. In this paper, the author studied the issues of formation of financial resources of the bank, analysis, structuring, effective management. The basis of the study was the work of Russian and foreign scientists and researchers groups. Total compare and analyze the essence of the definition of financial resources 9 scholars (groups of scientists), who were divided into three groups. The results of the study show that there is no single definition of the financial resources among the domestic and foreign scientists, but the interpretation of the concept of banking financial resources are very similar. The first group of scientists determines the bank resources as the total amount of funds available to the bank, which are used to carry out active operations. The second group of scientists gives a broader definition of the essence of banking resources. They believe that the bank is a collection of resources of their own and «foreign» (attracted) funds that are used to carry out active operations. The third group of scientists lead the most accurate, thorough and comprehensive definition of bank resources. According to them, banking resources - a combination of their own, attracted and borrowed funds, which are held by a bank and used to carry out banking activities. As a result of the study, the analysis of the three definitions given in three groups of authors, the rationale for allocation of loan and deposit resources, due to the nature of attraction Srokowo, management and cost of resources by the author formed the following definition of the financial resources of the bank. Thus, the financial resources of the bank - a collection of funds that are at the disposal of the bank and consist of equity capital of the bank, borrowed and borrowed funds, received by the bank on the terms of urgency (a certain date), against compensation, and used the latter to provide the full range of banking services. The practical implications. Implementation interpretation of financial resources of the bank according to the given definition of the author allow banking institutions weighed approach to resource mobilization policy, conservation and optimal proportions to maximize profits. Issues related to the financial resources of the bank, require further study to find new ways to supplement the financial resources of banks. Value/originality. As a result of the study, an analysis of the definitions of the three groups of authors highlight the necessity of loan and deposit resources, due to the nature of attraction Srokowo, management and cost of resources.
\end{abstract}

Key words. banks financial resources, borrowed funds, borrowings, liabilities.

JEL Classification: G21, G24, H74, G29

\section{1. Вступиение}

Основной и неотъемлемой частью ресурсов банков являются финансовые ресурсы. Банковское учреждение, как и мюбое юридическое мицо, требует стартового и текущего капитала Аця проведения экономической Аеятельности. Постоянная нехватка капитала в банках негативно отображается на Аоступности кредитных ресурсов, Аля Аругих участников экономики, и их стоимости. В условиях тяжёмого финансового кризиса, второго меньше чем за десять мет, существенного оттока капитала из банковской системы, потери доверия банковских учрежАений перед физическими мицами и юри-
Аическими мицами, особенно важными и актуамьными направлениями работы являются возврат капитала в банки, разработка актуальных и эффективных метоАов управления финансовыми ресурсами, повышения надёжности банков и, как слеАствие, восстановление Аоверия к экономике страны в целом и к банковской системе в частности со стороны физических миц и субъектов хозяйствования. Учитывая то, что значительная часть финансовых ресурсов находиться вне банковской системы, банковским учрежАениям необходимо ответственно подойти к вопросам управления финансовыми ресурсами, их классификации по разным признакам, Аля

\footnotetext{
Corresponding author:

${ }^{1}$ Department of Accounting in Credit and Budgetary Institutions and Economic Analysis,

Kyiv National Economic University named after Vadym Hetman.

E-mail: alexey.mishnyov@ukr.net
} 
формирования взвешенной политики эффективного использования имеющихся среАств и созАания условий Аля возврата капитала в банковскую систему. Банковская система Украины состоит из Национального банка Украины и Аругих банков, а также филей иностранных банков, созАанных и действующих на территории Украины согласно Закону Украины «О банках и банковской деятельности» и Аругих Законов Украины (The Law of Ukraine «On Banks and Banking», 2000). ОАной из функций банковской системы явмяется трансформационная - мобилизация свободных среАств на финансовом рынке и распределение их межАу нужАающимися субъектами экономической Аеятельности. Следовательно, вопросы мобилизации среАств, их привлечение в банковскую систему, структурирование и распределение явмяются сверх важными и сверх актуальными.

Вопросами формирования финансовых ресурсов банка, их анализа, структурирования и эффективным управлением занимаются как отечественные, так и иностранные учёные, в частности М.A. Алексеенко (Alekseienko, 2002), А.Н. Мороз, М.И., Савцук (Moroz, Savluk, Pukhovkina, 2002), О.И, Ааврушин (Lavrushyn, Mamonova, Valentseva, 2009), О. Васюренко, И. ФеАосик (Vasiurenko, Fedosik, 2002), С.В. Землячёв (Zemliachov, 2009), А. Кутиғзе, О. Гранько (Kutidze, Hranko, 2009), В.И. Мищенко (Mishchenko, Slavianska, Koreneva, 2007), О.П. Присяжнюк (Prysiazhniuk, 2011).

По результатам провеАённого исслеАования, прихоАим к выводу что, учитывая катастрофическую ситуацию в экономике Украины, боевые Аействия на её территории, падения уровня Аоверия к банковской системе, существенное сокращения количества банков, сокращения инвестиций в страну с оАной стороны, и увеличения каналов привлечения среАств в банковскою систему в условиях развития IT технологий, разработку и внеАрение банками дополнительных услуг и возможностей управления финансовыми ресурсами с Аругой, процесс формирования финансовых ресурсов банками, анализ их сущности, структуры требует дополнительного изучения.

Целью Аанного исследования явмяется попытка проведения исследования сущности финансовых банковских ресурсов.

Решение поставленных в исследовании задач позвомит внеАрить эффективную систему формирования, структурирования, управления и использования финансовых ресурсов банка с целью эффективного распределения финансовых ресурсов, всестороннего анализа, снижения стоимости использования, преАложения выгодных условий размещения ресурсов субъектам экономической Аеятельности.

\section{2. Ресурсная база банка и банковские финансовые ресурсы}

Банковские финансовые ресурсы явмяют собой опору, опорный столб деятельности отдельного банка и всей банковской системы в целом. Толковый словарь опредемяет ресурс - як запасы чего-нибудь, которые можно использовать при необходимости. Банкам, как и мюбым субъектам хозяйствования, необходимый запас среАств, Аля проведения своей деятельности. Но, несмотря на важность Аанной экономической категории, еАиного определения относительно ресурсной базы банков и финансовых банковских ресурсов нет. В своём исследовании С.В. Землячёв разделяет понятия «ресурсная база» и «банковские ресурсы», банковские финансовые ресурсы. Некоторые учёные отождествляют Аанные понятия, но это не верно. Амя Аостижения цели своей Аеятельности - УАовлетворения потребностей участников рынка в финансовых среАствах и получении прибыли, не всегАа используются только деньги. К банковским ресурсам относится не только финансовая составляющая, но и предоставление специфических консультативных ускуг, использование отАалённых способов управления собственными счетами с помощью IT технологий, стандарты качественного обслуживания и управления.

\section{3. Определение понятия «банковские ресурсы »}

Анализируя определение понятия «банковские ресурсы», предложенные разными учёными, автор пришёл к выводу, что еАиного устойчивого опредемения понятия финансовых банковских ресурсов не сформировано.

По мнению М.А. Алексеенка банковские ресурсы это совокупность Аенежных среАств и выраженных в Аенежной форме материальных, нематериальных и финансовых активов, которые пребывают в распоряжении банков и могут быть использованы ими Аля проведения активных операций и предоставления услуг (Alekseienko, 2002). Аанное определение явмяется общим и Ааёт обобщённое понятие про банковские финансовые ресурсы без разделения на составмяющее части, способами привлечения или сроками использования. Авторский коммектив поА руковоАством профессоров А.Н. Мороза и М.И. Савцука даёт такое определение банковским ресурсам - это совокупность Аенежных среАств, которые пребывают в распоряжении банков и могут быть использованы Аля проведения активных операций; разАичают привлечённые, позаимствованные и собственные ресурсы банка (Moroz, Savluk, Pukhovkina, 2002). Аанное определение явмяется более глубоким, привлечено внимание к природе происхожАения ресурсов. Комлектив учёных под руководством О.И. Ааврушина преАлагает такое определение: «Ресурсы коммерческих банков, или банковские ресурсы, преаставляют собой совокупность всех среАств, имеющихся в распоряжении банков и используемых Аля осуществления активных операций. Ресурсы коммерческого банка подразделяются на собственные и привлечённые среАства (Lavrushyn, 
Mamonova, Valentseva, 2009)». В этом определении акцентируют внимание на собственности используемых ресурсов, но не описаны механизмы привлечения среаств в банковские учреждения. О. Васюренко и И. ФеАосик отмечают, что ресурсы коммерческого банка - это совокупность собственных, привлечённых и целевых средств банка, которые находятся в непосреАственном его распоряжении и используются по его усмотрению Аля осуществления полномасштабной банковской деятельности (Vasiurenko, Fedosik, 2002). Аанное определение имеет общий характер Аля теоретического понимания сущности финансовых ресурсов банка. Юридическую сторону определения категории банковские ресурсы освещает С.В. Землячёв: ресурсы коммерческого банка - это среАства, которыми распоряжается банк и использует Аля обеспечения своей Аеятельности на коммерческих началах и в соответствии с требованиями регумятивных органов (Zemliachov, 2009). Авторы $\Lambda$. Кутидзе и О. Гранько придерживаются мысли, что ресурсы коммерческих банков - совокупность собственного капитала и привлечённого банком в результате провеАения пассивных операций и активно-пассивных операций, а также средств, которые есть в его распоряжении и могут быть использованы Аля активных операций (Kutidze, Hranko, 2009). В Аанном случае приведены способы привлечения среАств в коммерческий банк и их целевое назначение. ОАин из авторов Банковской энциклопедии В.И. Мищенко Ааёт глубокое и структурированное определение исследуемой категории: банковские ресурсы (bank resources) - совокупность Аенежных среАств, которые пребывают в распоряжении банка и используются им Аля выполнения своих функций и операций. Банковские ресурсы - это финансовые ресурсы банка, которые состоят из собственных, привлечённых и позаимствованных средств (Mishchenko, Slavianska, Koreneva, 2007). В Аанном определении раскрыта структура финансовых ресурсов банков и их целевое назначение. Подобную точку зрения имеет О.П. Присяжнюк. Он определяет ресурсы коммерческого банка, как его собственный капитац, привлечённый и позаимствованный капитал, а также самостоятельный источник собственных средств банка (Prysiazhniuk, 2011). В Аанном опреАелении введена отдельная составмяющая, как «самостоятельный источник собственных среАств», которая не встречается у Аругих учёных. Сравнение приведённых определений понятия банковские ресурсы привеАено в таблице 1.

Сравнивая приведённые разными учёными и группами учёных опредемения, автор пришёл к выводу, что все приведённые трактовки похожи по своей сути. ПоА ресурсами банков авторы рассматривают среАства, то есть конкретный финансовый высоколиквиАный актив. Разница межАу взгляАами разных учёных состоит в трактовке структуры и природы исследуемого понятия. По взглядам, привеАённые опреАеления учёных и групп учёных, можно разАелить на три группы.

Первая группа учёных, в составе Алексеенка М.A. (Alekseienko, 2002) и Землячёва С.B. (Zemliachov, 2009) приводит обобщённое понятие. Они опреде-

\section{Таблиця 1}

\section{Сравнение определения категории банковские ресурсы}

\begin{tabular}{|c|c|}
\hline Учёный/Группа учёных & Определения понятия банковские ресурсы \\
\hline Алексеенко М.А. & $\begin{array}{l}\text { Банковские ресурсы -это совокупность Аенежных средств и выраженных в Аенежной форме } \\
\text { материальных, нематериальных и финансовых активов, которые пребывают в распоряжении банков и } \\
\text { могут быть использованы ими дмя проведения активных операций и предоставления услуг. }\end{array}$ \\
\hline $\begin{array}{l}\text { Мороз А.М., } \\
\text { Савцук М.И. }\end{array}$ & $\begin{array}{l}\text { Банковские ресурсы - это совокупность денежных средств, которые пребывают в распоряжении } \\
\text { банков и могут быть использованы Аля проведения активных операций; размичают привлечённые, } \\
\text { позаимствованные и собственные ресурсы банка. }\end{array}$ \\
\hline Ааврушин О.И. & $\begin{array}{l}\text { Ресурсы коммерческих банков, или банковские ресурсы, представляют собой совокупность всех } \\
\text { средств, имеющихся в распоряжении банков и используемых Аля осуществления активных операций. } \\
\text { Ресурсы коммерческого банка подразделяются на собственные и привлечённые среАства. }\end{array}$ \\
\hline $\begin{array}{l}\text { Васюренко О., } \\
\text { Федосик И. }\end{array}$ & $\begin{array}{l}\text { Ресурсы коммерческого банка - это совокупность собственных, привцечённых и целевых средств } \\
\text { банка, которые находятся в непосредственном его распоряжении и используются по его усмотрению Аля } \\
\text { осуществцения полномасштабной банковской деятельности. }\end{array}$ \\
\hline Земмячёв С.В. & $\begin{array}{l}\text { Ресурсы коммерческого банка - это среАства, которыми распоряжается банк и использует } \\
\text { Аля обеспечения своей деятельности на коммерческих началах и в соответствии с требованиями } \\
\text { регулятивных органов. }\end{array}$ \\
\hline $\begin{array}{l}\text { Кутилзе } \Lambda ., \\
\text { Гранько О. }\end{array}$ & $\begin{array}{l}\text { Ресурсы коммерческих банков - совокупность собственного капитала и привмечённого банком в } \\
\text { результате проведения пассивных операций и активно-пассивных операций, а также средств, которые есть } \\
\text { в его распоряжении и могут быть использованы дмя активных операций. }\end{array}$ \\
\hline Мищенко В.И. & $\begin{array}{l}\text { Банковские ресурсы (bank resources) - совокупность Аенежных средств, которые пребывают в } \\
\text { распоряжении банка и используются им Аля выполнения своих функций и операций. Банковские } \\
\text { ресурсы - это финансовые ресурсы банка, которые состоят из собственных, привцечённых и } \\
\text { позаимствованных средств }\end{array}$ \\
\hline Присяжнюк О.П. & $\begin{array}{l}\text { Ресурсы коммерческого банка - собственный капитац, привлечённый и позаимствованный капитац, а } \\
\text { также самостоятельный источник собственных среАств банка. }\end{array}$ \\
\hline
\end{tabular}


мяют банковские ресурсы, как общий объём денежных среАств, имеющийся в распоряжении банка, которые используются Аля проведения активных операций. Такое определение Ааёт возможность понять общую сущность категории, не угмубцяясь в её структуру, назначение и способы привлечения.

Вторая группа учёных даёт более широкое опредемение сущности банковских ресурсов. О.И. Ааврушин (Lavrushyn, Mamonova, Valentseva, 2009), О. Васюренко, И. Федосик (Vasiurenko, Fedosik, 2002), А. КутиАзе, О. Гранько (Kutidze, Hranko, 2009) считают, что банковскими ресурсами явмяется совокупность собственных и «чужих» (привлечённых) среАств, которые используются Аля проведения активных операций. В Аанном определении отмечается собственник используемых банком ресурсов, что в свою очередь поднимает вопрос механизмов привлечения среАств и сроков их использования. Такое определение раскрывает сущность банковского учреждения, как такого, которое проводит свою основную Аеятельность за счёт ресурсов, полученных от Аругих миц.

Третья группа учёных, в которую входят А.Н. Мороз, М.И. Савлук (Moroz, Savluk, Pukhovkina, 2002), В.И. Мищенко (Mishchenko, Slavianska, Koreneva, 2007), О.П. Присяжнюк (Prysiazhniuk, 2011) приводит наиболее точное, основательное и всестороннее опреАеление понятия банковские ресурсы. По их мнению, банковские ресурсы - это совокупность собственных, привлечённых и позаимствованных среАств, которые находятся в распоряжении банка и используются Аля проведения банковской Аеятельности. Аанное утвержАение указывает на право собственности на ресурсы, способы привлечения и их целевое назначение. В Аанной трактовке исслеАуемого понятия выдемено Аепозитную и кредитную природу банковских ресурсов. Средства со ссудной природой (позаимствованные средства), оказываются в банке по его инициативе, путём получения кредитов в НБУ или в Аругом банке. Аепозитная природа среАств (привлечённые среАства) определяется инициированием получения банком среАств третьими мицами - физическими или юридическими мицами путём оформления текущих или депозитных счетов в банковских учреждениях на условиях, определённых непосреАственно банковским учреждением. Сравнение подходов к опреАелению сущности банковских ресурсов по группам привеАено на рисунке 1.

Проведённое исследование позволяет сделать вывоА, что третья группа авторов привела наиболее точное и развёрнутое определение понятия банковских финансовых ресурсов. Выделение кредитных и депозитных среАств явмяется существенным и важным.

\section{4. Важность ВыАеления ссУАных и Аепозитных ресурсов}

Аля обывателя разницы межАу ссуАными и креАитными средствами - нет, его интересует максимальный процент по депозитам, и минимахьный по креАитам. Специалисты банковского Аела обязательно Аолжны выделять эти составцяющие части финансовых ресурсов банков, Аля наАлежащего их учёта, анамиза и контроля.

С точки зрения бухгалтерского учёта оба виАа Аанной задолженности относятся к кредиторской, учитываются на счетах 1 класса. С юридической и экономической точки зрения - разница существенная. Юридически, заимствования кредитных среАств оформляются кредитным Аоговором, сторонами которого выступают банковское учрежАение, как заёмщик, и а Аругой банк или НБУ, как креАитор. Привлечённые среАства оформляются Аоговором банковского вкцада межАу банковским учрежАением и вкладчиком. Вкладчиками могут быть как физические мица, так и юридические мица, Аругие банки, НБУ. Юридически, описываемые правоотношения регумируются Цивильным кодексом Украины.

В зависимости от природы финансовых ресурсов: собственного капитала, позаимствованных или привлечённых среАств - разным будет срок использования ресурса и его стоимость. Собственный капитал - собственность банка, постоянно находится в его распоряжении и не требует пиаты за его использования. Срок использования привлечённых - Аепозитных среАств

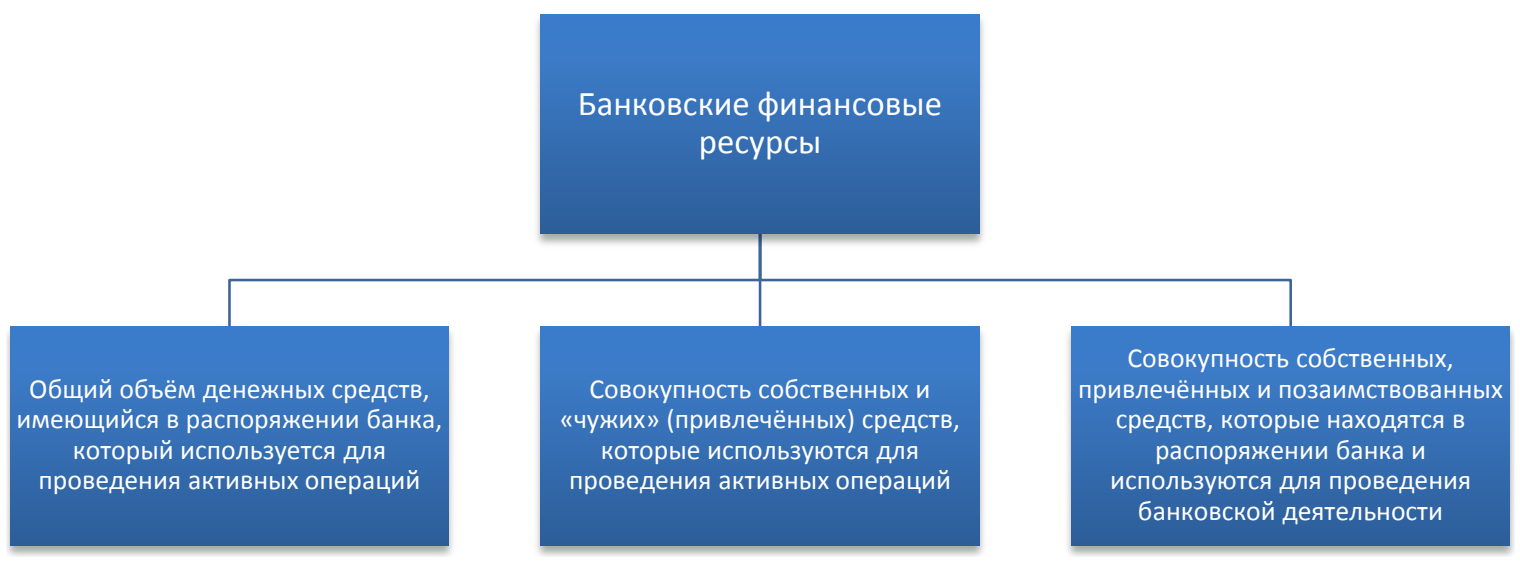

Рис. 1. Сравнение подходов к опредемению сущности банковских ресурсов 
регулируется Аоговором банковского вклада. СреАства могут привлекаться на краткосрочный и долгосрочный срок. Пиатой за использования Аепозитных среАств выступает процент, который устанавливается банком и закрепляется в договоре. КреАитные - ссудные среАства явцяются наиболее Аорогими. Плата за них устанавливается кредитором и принимается заёмщиком. Поскольку банковские учреждения рассчитывают на прибыль в виле разницы процентов по кредитам и процентам по Аепозитам (обычно процент по кредитам выше чем по Аепозитам, в результате чего и формируется маржа), то кредитные среАства в основном будут Аороже, чем Аепозитные. Соответствующие условия побужАают банки к поиску более Аешёвых - Аепозитных ресурсов.

Аругим важным вопросом использования банковскими учреждениями финансовых ресурсов есть следование установленных Национальным банком Украины отдельных нормативов, которые регулируют соотношение объёмов капитала, кредитных и депозитных средств. Соответствующие нормативы определены Инструкцией про регулирование Аеятельности банков в Украине. Нарушение утверждённых значений нормативов приведёт к вынесению предупреждений, штрафов, и, как последний аргумент, выведение банка с рынка.

В результате проведённого исследования, анализа трёх приведенных определений тремя группами авторов, обоснования необходимости выделения ссуАных и Аепозитных ресурсов, ввиАу специфики срокового привлечения, управления и стоимости ресурсов автором сформировано следующее определение финансовых банковских ресурсов. Итак, финансовые банковские ресурсы - это совокупность денежных среАств, которые находятся в распоряжении банка и состоят из собственного капитала банка, позаимствованных и привлечённых средств, полученных банком на условиях срочности (определённого срока), оплатности и используются послеАним Аля преАоставления всего банков. спектра банковских ускуг.

\section{5. ВЫВОАЫ}

В условиях тяжёлого финансового кризиса, существенного оттока среАств из банковской системы, военных действий на территории государства, значительной потери Аоверия субъектов экономических отношений особенно важным и актуальным является привлечения банками финансовых ресурсов, эффективное управление ними и обеспечение функционирования национальной экономики путём реализации трансформационной функции банковской системы, а именно мобилизации свободных финансовых ресурсов и распределение последних относительно потребностей. Роль финансовых ресурсов переоценить невозможно. Финансовые ресурсы являются основой деятельности мюбого субъекта экономики, в том числе банковского учреждения. Среди отечественных и зарубежных учёных нет единого определения финансовых ресурсов, но трактовки понятия финансовые банковские ресурсы очень похожи. Автором преАложено собственное опреАеление финансовых банковских ресурсов, а именно: это совокупность Аенежных среАств, которые нахоАятся в распоряжении банка и состоят из собственного капитала банка, позаимствованных и привлечённых среАств, полученных банком на условиях срочности (определённого срока), оплатности и используются последним Аля предоставления всего спектра банковских услуг. Предложенное определение акцентирует внимание на разной природе среАств, получаемых банками, их стоимости, срока использования и регумятивного аспекта. ВнеАрение трактовки финансовых банковских ресурсов согласно приведённого опреАемения позволит банковским учреждениям взвешено подойти к политике привлечения ресурсов, сохранения оптимальных пропорций и получения максимальной прибыли. Вопросы, связанные с финансовыми банковскими ресурсами, требуют Аальнейшего изучения Аля поиска новых путей пополнения финансовых ресурсов

\section{References}

Alekseienko, M.D. (2002). Capital Bank: Theory and Practice. Monograph, KNEU, 176 p.

Lavrushyn, O.I., Mamonova, I.D., Valentseva, N.I. (2009). Banking, Textbook, issue 8, 768 p.

Kutidze, L., Hranko, O. (2009). Structure of raising funds commercial bank: deformation under the influence of the global financial crisis. Economic space Journal. 23/2: 131-139.

Mishchenko, V.I., Slavianska, N.H., Koreneva O.H. (2007). Banking, Textbook, issue 2.

Moroz, A.M., Savluk, M.I., Pukhovkina, F. (2002). Banking transactions, Textbook, issue 2, 476 p.

Prysiazhniuk, O.P. (2011). Sources of and strengthening the resource base of commercial banks in Ukraine. Retrieved from: http://nbuv/gov/ua/PORTAL/soc gum/pprbsu/2011 31/1131 27.pdf.

The Law of Ukraine «On Banks and Banking» (2000). - Retrieved from:http://zakon2.rada.gov.ua/laws/ show/2121-14

Vasiurenko, O., Fedosik, I., (2002). Resource potential commercial bank. Bank activity Journal. 1: 58-64

Zemliachov, S.V. (2009). The essence of the sources of value and resource base of commercial banks. Scientific Journal: finance, banks, investment. 3: 68-74. 


\section{Алексей МИШНЕВ}

\section{СУЩНОСТЬ ФИНАНСОВЫХ РЕСУРСОВ БАНКОВ И ИХ КЛАССИФИКАЦИЯ}

Аннотация. Целью работы является попытка проведения исследования сущности финансовых банковских ресурсов. Методика. В данной работе автором исследованы вопросы формирования финансовых ресурсов банка, их анализа, структурирования, эффективного управления. Базой исследования стали работы отечественных и зарубежных учёных и групп учёных. Всего сравнено и проанализировано определения сущности финансовых ресурсов 9 учёных (групп учёных), которые были разделены на три группы. Результаты проведённого исследования показывают, что среди отечественных и зарубежных учёных нет единого определения финансовых ресурсов, но трактовки понятия финансовые банковские ресурсы очень похожи. Первая группа учёных определяет банковские ресурсы, как общий объём денежных средств, имеющийся в распоряжении банка, которые используются для проведения активных операций. Вторая группа учёных даёт более широкое определение сущности банковских ресурсов. Они считают, что банковскими ресурсами является совокупность собственных и «чужих» (привлечённых) средств, которые используются для проведения активных операций. Третья группа учёных приводит наиболее точное, основательное и всестороннее определение понятия банковские ресурсы. По их мнению, банковские ресурсы - это совокупность собственных, привлечённых и позаимствованных средств, которые находятся в распоряжении банка и используются для проведения банковской деятельности. В результате проведённого исследования, анализа трёх приведенных определений тремя группами авторов, обоснования необходимости выделения ссудных и депозитных ресурсов, ввиду специфики срокового привлечения, управления и стоимости ресурсов автором сформировано следующее определение финансовых банковских ресурсов. Итак, финансовые банковские ресурсы - это совокупность денежных средств, которые находятся в распоряжении банка и состоят из собственного капитала банка, позаимствованных и привлечённых средств, полученных банком на условиях срочности (определённого срока), оплатности и используются последним для предоставления всего спектра банковских услуг. Практическое значение. Внедрение трактовки финансовых банковских ресурсов согласно приведённого автором определения позволит банковским учреждениям взвешено подойти к политике привлечения ресурсов, сохранения оптимальных пропорций и получения максимальной прибыли. Вопросы, связанные с финансовыми банковскими ресурсами, требуют дальнейшего изучения для поиска новых путей пополнения финансовых ресурсов банков. Значение/оригинальность. В результате проведённого исследования, анализа приведенных определений тремя группами авторов, обоснована необходимость выделения ссудных и депозитных ресурсов, ввиду специфики срокового привлечения, управления и стоимости ресурсов. 